\title{
Taking Stock and Re-Examining the Role of Science Communication
}

\author{
Joseph Roche ${ }^{1 *}$, Rosa Arias $^{2}$, Laura Bell ${ }^{1}$, Marco Boscolo ${ }^{3}$, Alessandra Fornetti ${ }^{4}$, \\ Antti Knutas ${ }^{5}$, Frank Kupper ${ }^{6}$, Joana Magalhães ${ }^{2}$, Ilda Mannino ${ }^{4}$, Isabel Mendoza ${ }^{7}$, \\ Carolina Moreno-Castro ${ }^{7}$, Kathryn Murphy ${ }^{1}$, Jason Pridmore ${ }^{8}$, Fiona Smyth ${ }^{1}$, \\ Elisabetta Tola ${ }^{3}$, Marina Tulin ${ }^{8}$, Emma Weitkamp ${ }^{9}$ and Annika Wolff ${ }^{5}$ \\ ${ }^{1}$ School of Education, Trinity College Dublin, Dublin, Ireland, ${ }^{2}$ Science for Change, Barcelona, Spain, ${ }^{3}$ Formicablu, Bologna, Italy, \\ ${ }^{4}$ TEN Program on Sustainability, Venice International University, Venice, Italy, ${ }^{5}$ School of Engineering Science, LUT University, \\ Lappeenranta, Finland, ${ }^{6}$ Athena Institute, VU University, Amsterdam, Netherlands, ${ }^{7}$ Institute on Social Welfare Policy, University of \\ Valencia, Valencia, Spain, ${ }^{8}$ Department of Media and Communication, Erasmus University Rotterdam, Rotterdam, Netherlands, \\ ${ }^{9}$ Science Communication Unit, University of the West of England, Bristol, United Kingdom
}

Keywords: swafs, science with and for society, horizon 2020, horizon europe, science journalism, public engagement, science communication, citizen science

Eight science communication research projects have been funded by the European Commission since 2018. These projects are a response to one of the European Commission's 'Science with and for Society' (SwafS) funding calls — "SwafS-19: Taking stock and re-examining the role of science communication." Together these projects have received almost $€ 10$ million in research funding, and each has been affected to some extent by the COVID-19 global pandemic. This paper provides an overview of the eight projects, how they adapted to the challenges caused by the pandemic, and the subsequent implications for science communication policy and research funding.

\section{INTRODUCTION}

\section{SwafS-19}

Taking Stock and Re-Examining the Role of Science Communication is a Research and Innovation Action in Section 16, "Science with and for Society" (SwafS), of the European Commission's 2018-2020 Horizon 2020 Work Programme (European Commission, 2020). Previous iterations of SwafS, under the European Framework programmes FP6 and FP7, were titled "Science and Society," and "Science in Society," respectively (Delaney and Tornasi, 2020). SwafS-19 is dedicated to assessing science communication and its perception by citizens to construct a knowledge base that will support the ultimate aim of the Work Programme: to build trust in science and empower citizens through enhanced accuracy of information, more effective communication, and multidirectional knowledge flows between all stakeholders. This builds on two decades of scholars in the field highlighting the need for empirical research and resources to help improve and support science communication (Treise and Weigold, 2002; Nisbet and Scheufele, 2009; Trench and Bucchi, 2010; Fischhoff \& Scheufele, 2013). The potential research agenda for science communication has included advocates for better evaluation of science communication (Jensen, 2014) and large-scale public engagement projects (Roche et al., 2017; Jensen et al., 2021), improved strategic communication (Besley, 2020), and the need to find synergies between science communication, science education, public engagement, citizen science, and related research fields (Stilgoe, Lock, and Wilsdon, 2014; Baram-Tsabari and Osborne, 2015; Roche et al., 2020).

The SwafS-19 funding call was launched in 2018 as part of the European Commission's eighth framework programme, Horizon 2020: the world's largest multinational research funding programme (Abbott, 2020). The SwafS-19 call was renewed annually for three years, with the final round of submissions invited in April 2020. The 26 applications received in 2020 represented a 
TABLE 1 | All eight projects funded under the European Commission funding call H2020-SwafS-19: "Taking stock and re-examining the role of science communication."

\begin{tabular}{|c|c|c|c|c|}
\hline Name & Timeframe & Partner countries & Budget & Website \\
\hline CONCISE & 01.12.18-31.01.21 & Spain, Italy, Slovakia, Poland, Portugal & $€ 1,198,337.50$ & concise-h2020.eu \\
\hline RETHINK & $01.01 .2019-31.12 .2021$ & Netherlands, Belgium, United Kingdom, Germany, Italy, Denmark & $€ 1,198,771.25$ & rethinkscicomm.eu \\
\hline QUEST & 01.02.2019-31.07.2021 & Italy, Norway, United Kingdom, Estonia, France, Ireland & $€ 1,194,227.50$ & questproject.eu \\
\hline TRESCA & $01.01 .2020-30.04 .2022$ & Netherlands, Spain, Italy, Austria, United Kingdom, Germany & $€ 1,199,601.25$ & trescaproject.eu \\
\hline NEWSERA & $01.01 .2020-31.12 .2022$ & Spain, Italy, Portugal & $€ 1,299,250.00$ & newsera2020.eu \\
\hline ParCos & $01.01 .2020-31.12 .2022$ & Finland, Belgium, United Kingdom & $€ 1,379,772.50$ & parcos-project.eu \\
\hline ENJOI & $01.01 .2021-31.12 .2023$ & Italy, Spain, Portugal, Netherlands, Belgium & $€ 1,222,462.50$ & enjoiscicomm.eu \\
\hline GlobalSCAPE & 01.03.2021-28.02.2023 & Ireland, Netherlands, Belgium, United Kingdom & $€ 1,199,937.50$ & global-scape.eu \\
\hline
\end{tabular}

substantial increase from the previous years; six applications were submitted in 2018, and 18 in 2019. From 49 submissions over three years, a total of eight projects were funded, with an overall investment of almost $€ 10$ million (Table 1).

The relevance of the objectives of SwafS-19 was increased in the first instance by the challenges posed directly by the global pandemic, and further heightened by its ripple effects. By extension, the individual objectives of the eight projects assumed a new immediacy during an era marked by rapid and unprecedented change and marred by uncertainty and doubt. This article considers how these projects have contributed to evidence-based science communication in the COVID-19 era by outlining the aims of the eight projects and by contextualising them in light of how the world has changed in the wake of the most widespread public health crisis of the modern era.

\section{INTERNATIONAL SCIENCE COMMUNICATION RESEARCH IN THE COVID-19 ERA}

Three projects-CONCISE, RETHINK, and QUEST-were awarded funding in the first SwafS-19 funding call in 2018. Three more-TRESCA, NEWSERA, and ParCos-received funding in 2019, and were initiated in early 2020. The final two-ENJOI and GlobalSCAPE-were funded in 2020 and officially began in 2021. Each project is subdivided into interconnected tasks and work packages, with associated milestones and deliverables. The eight projects tackle the overall objectives of the SwafS-19 funding call in different ways.

CONCISE aims to gain greater understanding of, and insight into, the role of science communication in shaping public perceptions and opinions, and to assess citizens' trust in institutional sources and channels of information. The project gathered perspectives from 500 citizens across five EU cities on four pressing social and science issues: vaccines, complementary and alternative medicine use, food safety, and climate change. In view of the COVID-19 pandemic, these topics are more relevant than ever. Publications arising from the project findings explore participatory approaches to engaging the public with climate change communication (Dziminska et al., 2021); analyse how science communication is mediated (Delicado et al., 2021); and assess citizen trust in science (Brondi et al., 2021). Published in six languages, the CONCISE Policy Brief is one of a number of openaccess resources available.

RETHINK focuses on understanding the digital science communication landscape and how people navigate it in order to make it more open, inclusive, and adaptive. The project has established communities of practice, known as "Rethinkerspaces", in seven EU countries. The COVID-19 pandemic shifted these communities into digital spaces, and allowed RETHINK to explore public knowledge in the context of "science in the making" and the sources people turned to. RETHINK has produced publications that examine the ecology of digital science communication (Weitkamp et al., 2021); characterise the online practices of scientists undertaking public engagement (Roedema et al., 2021); and chart the implementation of a Delphi study of international science communication scholars (Fähnrich, 2021). Forthcoming work will address quality criteria for science communication in diverse contexts, and will produce training materials for science communicators in the context of COVID-19.

QUEST seeks to better understand the dynamics of contemporary science communication through the three strands of journalism, social media, and science museums. It brings together scientists, science communication professionals, and policy makers in designing tools to support quality science communication, and thus enhance public engagement and trust. QUEST responded to the pandemic by adapting its co-design methodology and moving its activities online, and the project was extended by six months in order to properly disseminate its results. QUEST has produced a number of publications, including an exploration of the fragmented landscape of European science communication (Davies et al., 2021); a study of quality indicators in science communication (Olesk et al., 2021); and insights into the tools created to support science communicators (Mannino et al., 2021). A collection of toolkits for scientists and science communication professionals are available online.

TRESCA focuses primarily on social science by exploring concerns about the effects of misinformation, disinformation, and over-information in relation to public trust in (social) science communication. The project employs large scale experimental survey research as well as qualitative, deliberative research in its methodology, with particular emphasis on addressing misinformation and digital safety; environmental health; automation and the future of skills and work. It responded to the global pandemic by specifically studying how increased online 
consumption of health information affects trust in science communication and integrating those findings into a Massive Open Online Course to facilitate dialogue between the scientists, journalists, and policy makers navigating the digital environment via visual communication.

NEWSERA analyses and evaluates the complexities of science communication in citizen science as they pertain to data journalism and the quadruple helix of science, policy, industry, and societal stakeholders. The project's focus is on citizen science initiatives across Europe, taking into account iterative feedback loops and the multidirectional flow of information, as well as the specific tools and strategies required by different stakeholders. The COVID-19 pandemic has had a surprisingly positive impact on the project. The move from face-to-face to virtual events has facilitated a significant increase in the number of citizen science projects participating in \#CitSciComm Labs-from four projects per lab to 38 -as well as an increase in the number of representative stakeholders involved in the co-creation activities within each lab. The labs have also been delocalised to the countries involved, enabling the activities to be conducted in local languages.

ParCos utilises arts-based methods to create interactive stories and narratives from scientific data. Its central aim is to convert science communication into a widely accessible and cultural activity, and as such, the project adopts an iterative and co-creative process in order to change the manner in which science is communicated. The project is designed to enable audiences to interpret scientific data for themselves, and the contribution of diverse perspectives is encouraged. The outbreak of COVID-19 pushed ParCos to shift the majority of its activities online. Conducting data drama and other artsbased practices online was particularly difficult, because relationship-building and trust are crucial to the experience. ParCos was able to rise to this challenge by creating a fully immersive theatre experience that was streamed live to participants at home.

ENJOI centres on standards, principles, and indicators in science communication in order to address the prevalence of misinformation. Current issues, such as the global pandemic and the climate crisis are highlighted as key areas where misinformation must be tackled within a reliable framework of policies and actions that are grounded in science. Journalism is a core focus of the project, and the pandemic has underlined the significance of journalists as mediators in influencing and determining both public debate and public trust in science. Along with a series of public reports and research papers, the legacy of ENJOI will be a permanent platform for collaborative science journalism efforts, training, mutual learning, sharing of research outcomes, suggestions, and indications for policies. This 'Observatory for outstanding open science communication' aspires to become a reference point for innovations in science journalism and science communication, and their diffusion throughout the international community.

GlobalSCAPE uses diary studies to investigate the experiences of science communicators in parts of the world where their voices have been traditionally under-represented. Due to the pandemic, the project launch was delayed to plan for all aspects of the project to take place online if needed, including workshops, open educational resources, and policy briefings.

\section{DISCUSSION}

The inclusion of Science Communication as a topic under SwafS in the 2018-2020 Work Programme emerged from an interim evaluation of Horizon 2020, which demonstrated the need for greater engagement with civil society. In a subsequent report in 2020, science communication was recognised as central to the European Commission's goal of building trust between science and society in order to better meet societal challenges: "In essence, science communication entails presenting science related topics in a format which is designed for and understandable by the intended audience and remains faithful to the evidence" (Delaney and Tornasi, 2020, p. 15).

Since that report was published, at an early stage of the COVID-19 pandemic, the relationship between science and society has become increasingly salient. The initiation of the eight SwafS-19 science communication research projects during a public health crisis has provided a unique opportunity to explore how aspects of that relationship have changed. Perceptions of risk, uncertainty, credibility, and democracy have all received unprecedented attention in public discourse. The SwafS-19 objective of assessing science communication and its perception by citizens, with an underlying aim of building trust in science through clearer avenues of communication between all stakeholders, enhanced societal participation, and greater understanding of science, is tailor-made for confronting the challenges created by the pandemic.

The overall pre-pandemic goal of the projects in 2018 was to take stock of current changes in the landscape of science, innovation, and its communication, and from this basis, to empower citizens through enhanced accuracy of information and more effective knowledge-transfer. This goal has become far more pressing in the intervening years. With the outbreak of the pandemic and need for swift, drastic, and often contested decision-making, it has also become evident that effective science communication must be a fundamental component of policy-making, especially in terms of emergency and disaster management and climate communication (Kahan, 2012; Chinn et al., 2020; Koerber, 2021). The pandemic has also brought about dramatic changes to how large-scale research projects can be implemented, with wholesale conversion to online conferences and virtual events (Amemado, 2020; Klöwer et al., 2020; Niner et al., 2020; Roche et al., 2021a; Roche et al., 2021b). These challenges have highlighted that there is more need than ever for researchers and practitioners to harness their shared science communication expertise (Jensen and Gerber, 2020).

The SwafS-19 projects have produced research outputs to help reinterpret and rethink science communication in light of this ever-changing landscape (Kupper et al., 2021). Each project maintains a separate website so that project details, outputs, and data from the ongoing research remain publicly accessible. The links to the project websites are listed in Table 1. The projects 
are not without limitations. To adhere to the guidelines of the Horizon 2020 Work Programme, each project consortium involves organisations from at least three European countries and all project budgets are kept below $€ 1.4$ million. A more restrictive constraint is the timeline for the projects, with the work for each project expected to be completed within two to three years. This provides a challenge for longitudinal science communication research in particular.

Although SwafS will not be included as a standalone pillar of research funding in Horizon Europe (the next framework programme of the European Commission) many of the same themes and topics will be addressed in Section 11 of the Work Programme: "Widening participation and strengthening the European Research Area" (European Commission, 2021). Dedicated science communication funding may be reduced from the previous funding programme, but public engagement may receive more broad attention throughout Horizon Europe (Gerber, 2018; European Commission, 2021). As the eight SwafS19 projects continue to produce research outputs, support the field of science communication, and potentially influence future policy over the coming years, they will serve as an appraisal of whether the approach of funding large-scale science communication research projects is a worthwhile endeavour. Regardless of how the field is funded, the science communication community faces new responsibilities in how to communicate science in uncertain times. The pandemic

\section{REFERENCES}

Abbott, A. (2020). Farewell to Europe's Horizon 2020. Nature 588 (7838), 371. doi:10.1038/d41586-020-03516-6

Amemado, D. (2020). COVID-19: An Unexpected and Unusual Driver to Online Education. Int. higher Educ. 102, 12-14.

Andrews-Fearon, P., Götz, F. M., and Good, D. (2020). Pivotal Moment for Trust in Science - Don't Waste it. Nature 580, 456. doi:10.1038/d41586-020-01145-7

Baram-Tsabari, A., and Osborne, J. (2015). Bridging Science Education and Science Communication Research. J. Res. Sci. Teach. 52 (2), 135-144. doi:10.1002/ tea. 21202

Besley, J. C. (2020). Five Thoughts about Improving Science Communication as an Organizational Activity. Jcom 24 (3), 155-161. doi:10.1108/jcom-03-2020-0022

Brondi, S., Pellegrini, G., Guran, P., Fero, M., and Rubin, A. (2021). Dimensions of Trust in Different Forms of Science Communication: the Role of Information Sources and Channels Used to Acquire Science Knowledge. Jcom 20 (03), A08. doi: $10.22323 / 2.20030208$

Chinn, S., Hart, P. S., and Soroka, S. (2020). Politicization and Polarization in Climate Change News Content, 1985-2017. Sci. Commun. 42 (1), 112-129. doi:10.1177/1075547019900290

Davies, S. R., Franks, S., Roche, J., Schmidt, A. L., Wells, R., and Zollo, F. (2021). The Landscape of European Science Communication. Jcom 20 (03), 1-19. A01. doi:10.22323/2.20030201

Delaney, N., and Tornasi, Z. (2020). Science Communication - Achievements in Horizon 2020 and Recommendations on the Way Forward. Luxembourg: European Commission Directorate-General for Research and Innovation. Publications Office of the European Union.

Delicado, A., Rowland, J., and Estevens, J. (2021). Bringing Back the Debate on Mediated and Unmediated Science Communication: the Public's Perspective. Jcom 20 (03), A10. doi:10.22323/2.20030210

Dziminska, M., Mendoza, I., Pellegrini, G., and Rowland, J. (2021). Climate Change and Public Perception. Citizens' Proposals for Better Communication and Involvement. Jcom 20, A09. doi:10.22323/2.20030209 heralded a renewed call to rebuild trust between science and society, and it is up to researchers, educators, and policy-makers around the world to seize the opportunity to rebuild that trust (Andrews-Fearon et al., 2020).

\section{AUTHOR CONTRIBUTIONS}

JR, FS, KM, and LB led the conceptual design of the manuscript, while RA, MB, AF, AK, FK, JM, IMa, IMe, CM, JP, ET, MT, EW, and AW contributed to individual subsections. All authors reviewed the manuscript and provided comments and feedback.

\section{FUNDING}

This work was made possible with funding from the European Union's Horizon 2020 Research and Innovation Programme under Grant Agreement No. 101006436.

\section{ACKNOWLEDGMENTS}

The authors are grateful for the support of the European Union's Horizon 2020 Research and Innovation Programme and, in particular, the SwafS project officers and policy officers.

European Commission (2020). Horizon 2020 - Work Programme 2018-2020: Science with and for Society. (European Commission Decision C(2020)6320 of 17 September 2020). Retrieved June 20, 2021, Available at: https://ec.europa.eu/ research/participants/data/ref/h2020/wp/2018-2020/main/h2020-wp1820-swfs_ en.pdf.

European Commission (2021). Horizon Europe - Work Programme 2021-2022: Widening Participation and Strengthening the European Research Area. European Commission Decision C(2021)4200 of 15 June 2021. Retrieved June 20, 2021, Available at: https://ec.europa.eu/info/funding-tenders/opportunities/ docs/2021-2027/horizon/wp-call/2021-2022/wp-11-widening-participation-andstrengthening-the-european-research-area_horizon-2021-2022_en.pdf.

Faehnrich, B. (2021). Conceptualizing Science Communication in Flux - a Framework for Analyzing Science Communication in a Digital media Environment. Jcom 20 (03), Y02. doi:10.22323/2.20030402

Fischhoff, B., and Scheufele, D. A. (2019). The Science of Science Communication III. Proc. Natl. Acad. Sci. USA 116 (3), 7632-7633. doi:10.1073/ pnas. 1902256116

Gerber, A. (2018). RRI: How to 'mainstream' the 'upstream' Engagement. Jcom 17 (3), C06. doi:10.22323/2.17030306

Jensen, A. M., Jensen, E. A., Duca, E., and Roche, J. (2021). Investigating Diversity in European Audiences for Public Engagement with Research: Who Attends European Researchers' Night in Ireland, the UK and Malta? PLoS ONE 16 (7), e0252854. doi:10.1371/journal.pone.0252854

Jensen, E. A., and Gerber, A. (2020). Evidence-based Science Communication. Front. Commun. 4 (78), 1-5. doi:10.3389/fcomm.2019.00078

Jensen, E. (2014). The Problems with Science Communication Evaluation. J. Sci. Commun. 13 (1), C04. doi:10.22323/2.13010304

Kahan, D. (2012). Why We Are Poles Apart on Climate Change. Nature 488 (7411), 255. doi:10.1038/488255a

Klöwer, M., Hopkins, D., Allen, M., and Higham, J. (2020). An Analysis of Ways to Decarbonize Conference Travel After COVID-19. Nature 583 (7816), 356-359.

Koerber, A. (2021). Is it Fake News or Is it Open Science? Science Communication in the COVID-19 Pandemic. J. Business Tech. Commun. 35 (1), 22-27. doi:10.1177/1050651920958506 
Kupper, F., Moreno-Castro, C., and Fornetti, A. (2021). Rethinking Science Communication in a Changing Landscape. Jcom 20 (03), E. doi:10.22323/ 2.20030501

Mannino, I., Bell, L., Costa, E., Di Rosa, M., Fornetti, A., Franks, S., et al. (2021). Supporting Quality in Science Communication: Insights from the QUEST Project. Jcom 20 (03), 1-22. A07. doi:10.22323/2.20030207

Niner, H. J., Johri, S., Meyer, H. J., and Wassermann, S. N. (2020). The Pandemic Push: Can COVID-19 Reinvent Conferences to Models Rooted in Sustainability, Equitability and Inclusion?. Socio. Ecol. Pract. Res. 2 (3), 253-256.

Nisbet, M. C., and Scheufele, D. A. (2009). What's Next for Science Communication? Promising Directions and Lingering Distractions. Am. J. Bot. 96 (10), 1767-1778. doi:10.3732/ajb.0900041

Olesk, A., Renser, B., Bell, L., Fornetti, A., Franks, S., Mannino, I., et al. (2021). Quality Indicators for Science Communication: Results from a Collaborative Concept Mapping Exercise. Jcom 20 (03), 1-17. A06. doi:10.22323/ 2.20030206

Roche, J., Bell, L., Galvão, C., Golumbic, Y. N., Kloetzer, L., Knoben, N., et al. (2020). Citizen Science, Education, and Learning: Challenges and Opportunities. Front. Sociol. 5 (613814), 1-10. doi:10.3389/ fsoc. 2020.613814

Roche, J., Bell, L., Hurley, M., D’Arcy, G., Owens, B., Jensen, A. M., et al. (2021a). A Place for Space: The Shift to Online Space Education during a Global Pandemic. Front. Environ. Sci. 9 (662947), 1-6. doi:10.3389/ fenvs.2021.662947

Roche, J., Bell, L., Martin, I., Mc Loone, F., Mathieson, A., and Sommer, F. (2021b). Science Communication through STEAM: Professional Development and Flipped Classrooms in the Digital Age. Sci. Commun. 43 (6), 805-813. doi: $10.1177 / 10755470211038506$

Roche, J., Davis, N., O’Boyle, S., Courtney, C., and O'Farrelly, C. (2017). Public Perceptions of European Research: an Evaluation of European Researchers' Night in Ireland. Int. J. Sci. Educ. B 7 (4), 374-391. doi:10.1080/ 21548455.2017.1371354
Roedema, T., Broerse, J., and Kupper, F. (2021). "Who Is Going to Believe Me, if I Say 'I'm a Researcher?" - Scientists' Role Repertoires in Online Public Engagement. Jcom 20 (03), A03. doi:10.22323/2.20030203

Stilgoe, J., Lock, S. J., and Wilsdon, J. (2014). Why Should We Promote Public Engagement with Science? Public Underst Sci. 23 (1), 4-15. doi:10.1177/ 0963662513518154

Treise, D., and Weigold, M. F. (2002). Advancing Science Communication. Sci. Commun. 23 (3), 310-322. doi:10.1177/107554700202300306

Trench, B., and Bucchi, M. (2010). Science Communication, an Emerging Discipline. J. Sci. Commun. 9 (3), C03. doi:10.22323/2.09030303

Weitkamp, E., Milani, E., Ridgway, A., and Wilkinson, C. (2021). Exploring the Digital media Ecology: Insights from a Study of Healthy Diets and Climate Change Communication on Digital and Social media. Jcom 20 (03), A02. doi: $10.22323 / 2.20030202$

Conflict of Interest: The authors declare that the research was conducted in the absence of any commercial or financial relationships that could be construed as a potential conflict of interest.

Publisher's Note: All claims expressed in this article are solely those of the authors and do not necessarily represent those of their affiliated organizations, or those of the publisher, the editors and the reviewers. Any product that may be evaluated in this article, or claim that may be made by its manufacturer, is not guaranteed or endorsed by the publisher.

Copyright ( 2021 Roche, Arias, Bell, Boscolo, Fornetti, Knutas, Kupper, Magalhães, Mannino, Mendoza, Moreno-Castro, Murphy, Pridmore, Smyth, Tola, Tulin, Weitkamp and Wolff. This is an open-access article distributed under the terms of the Creative Commons Attribution License (CC BY). The use, distribution or reproduction in other forums is permitted, provided the original author(s) and the copyright owner(s) are credited and that the original publication in this journal is cited, in accordance with accepted academic practice. No use, distribution or reproduction is permitted which does not comply with these terms. 